\title{
CHONDROMYXOID FIBROMA OF BONE
}

\author{
Leslie L. Ralph, Chesterfield, England \\ From the Radiological Department, Chesterfield Royal Hospital
}

Chondromyxoid fibroma was the name used by Jaffe and Lichtenstein (1948) to describe a group of eight bone tumours which had originally been diagnosed as chondrosarcoma, but which they thought to have a recognisably different histological pattern. In spite of the malignant appearance of some of the cells they considered the tumours to be benign and therefore worthy of separate classification. This new concept was accepted by Dahlin, Wells and Henderson (1953) and Dahlin (1956) who followed with an account of thirteen cases. Lichtenstein has now examined material from thirty-two cases, and each of these three authorities has devoted a chapter to this entity in his book on bone tumours (Dahlin 1957, Jaffe 1958, Lichtenstein 1959).

Altogether thirty-seven cases have now been reported, including Iwata and Coley's (1958) series of six and Wrenn and Smith's (1954) series of five. Only one case has been recorded in Britain (Hutchison and Park 1960).

There is general agreement about the more important features. Chondromyxoid fibroma presents like most bone tumours with pain, tenderness or swelling. There is no difference in sex incidence, but 80 per cent have occurred in patients less than thirty years of age, and particularly in those in the second and third decades of life. In a long bone the tumour develops in or near the metaphysis and sometimes crosses the epiphysial line. Most (thirty out of thirty-seven) have occurred in the lower limb, particularly around the knee but also in the bones of the foot. The proximal end of the tibia is by far the most common site.

The radiographic appearances are in many cases characteristic. There is a well defined bone defect in an eccentric position in or near the metaphysis of a long bone. As the tumour grows, the overlying cortex may be totally destroyed without any periosteal reaction or it may be stretched to a very thin and sometimes incomplete bony shell. The deep surface is usually marked by a thin layer of sclerosis, but sometimes there is a thicker layer of sclerosis shading off imperceptibly into normal bone away from the tumour. This deep surface may be lobulated, and the thickened ridges of bone in the tumour bed may give an appearance of fine trabeculation.

Recognition of the tumour depends largely upon the histological appearance. All authorities agree that this is distinctive, the abnormal tissue consisting of a mixture of fibrous, myxoid and chondroid areas of varying maturity with increased cellularity at the periphery. There are occasional foci of calcification, giant cells and cells with irregular nuclei. There is a tendency to lobulation. It is generally agreed that the tumour is benign, but it is stressed that the cells with irregular and multiple nuclei look deceptively malignant and may lead to a mistaken diagnosis of chondrosarcoma with the attendant possibility of unnecessary amputation. Dahlin (1956) has mentioned the possibility of a relationship between chondromyxoid fibroma and benign chondroblastoma, and it appears that tumours will occasionally be encountered where distinction between these two entities will be either difficult or impossible.

Case 1 of the present series was originally submitted to this Journal as a single case report. Other examples were, however, known to the Editorial Board and to Dr H. A. Sissons who, with Dr P. D. Byers, reviewed the histology in each case. All nine were, therefore, collected together for comparison with each other, and with previously reported cases. 


\section{CASE REPORTS}

Case 1 (Mr A. Dornan's case) -A man aged forty-five attended in April 1950 complaining that he had had pain in the left leg "for several years." On examination, the only abnormality was a localised area of tenderness over the posterior aspect of the fibula just below the head.

Radiographs showed an area of bone destruction in the fibula about two inches below the head and corresponding to the area of tenderness (Fig. 1). The lesion involved almost half the width of the bone and was well demarcated from surrounding normal bone by a thin layer of sclerosis. The tumour had destroyed the cortex as it extended into soft tissue, and although there was a small lip of elevated cortex at its margin there was no superficial shell of bone and the full extent of the tumour in the soft

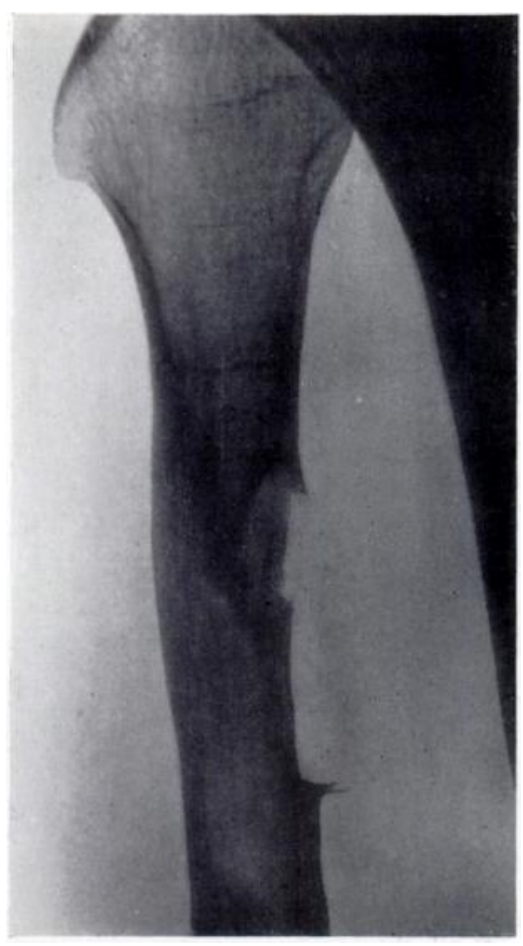

FIG. 1

Case 1-Radiograph of fibula showing superficial tumour destroying cortex and containing flecks of calcification. tissue could not be demonstrated. Within the tumour there were many small punctate spots of calcification, and the distribution of these suggested that the tumour was ovoid with approximately as much of it in the soft tissue as in the bone.

The diagnosis of a probably benign chondroma was made, but the possibility of malignancy was recognised.

In September 1950 the tumour and the affected part of the fibula were removed. Examination of the specimen (Dr J. L. Edwards) showed that the fibula contained a grey, encapsulated mass of fibrous semicystic consistency, in size $3 \times 2 \times 1$ centimetres. On the histological appearances a diagnosis of myxochondrosarcoma was made.

No further treatment was given. The patient returned six months later for treatment of acute right sciatica which was thought to be caused by prolapse of an intervertebral disc and which recovered rapidly. The left leg had given no trouble. He failed to attend for follow-up, but his family doctor reported in January 1959 (almost nine years after the first attendance) that the patient was alive and well with no evidence of recurrence of the tumour.

The radiographs were reviewed in 1958 during the course of a general review of many bone tumours and the resemblance to chondromyxoid fibroma was noted. On reconsideration of the original sections $\mathrm{Dr}$

Edwards agreed that this tumour probably was the same as those described as chondromyxoid fibroma. This opinion has been supported by Professor D. H. Collins and by Professor R. A. Willis after independent examination of the sections.

Histological examination (Professor D. H. Collins) showed the tumour to be subperiosteal in location, as was suggested by the radiograph. Between overlying muscle and tumour there was no bone but only a few laminae of fibrous membrane. Deep to the growth there was compact cortical bone, its outline scalloped by the growth. Corresponding with the radiographic appearance of opacities in the extra-osseous tumour there were in the superficial part of the growth foci of apparent calcification showing as intensely basophilic masses even in the decalcified section. These foci had formed within the hyaline chondroid masses which were ribbons or islets of sparsely cellular eosinophilic homogeneous material, not much like cartilage but having more the appearance of chondroid than of osteoid tissue (Fig. 2). The bulk of the tumour had the aspect of a myxoma, with elongated, curved or triradiate fibroblastic cells of indistinct cell outline lying in a diffuse palely eosinophilic matrix containing delicate fibrils and 
vacuoles (Fig. 3). There was more compact cellularity at some points on the margin of the tumour lobules. There were no giant cells or haemosiderin.

$\mathrm{Dr} \mathrm{H}$. A. Sissons also examined a section of this tumour but did not consider the appearances diagnostic of chondromyxoid fibroma. Rather excessive decalcification made further identification difficult.

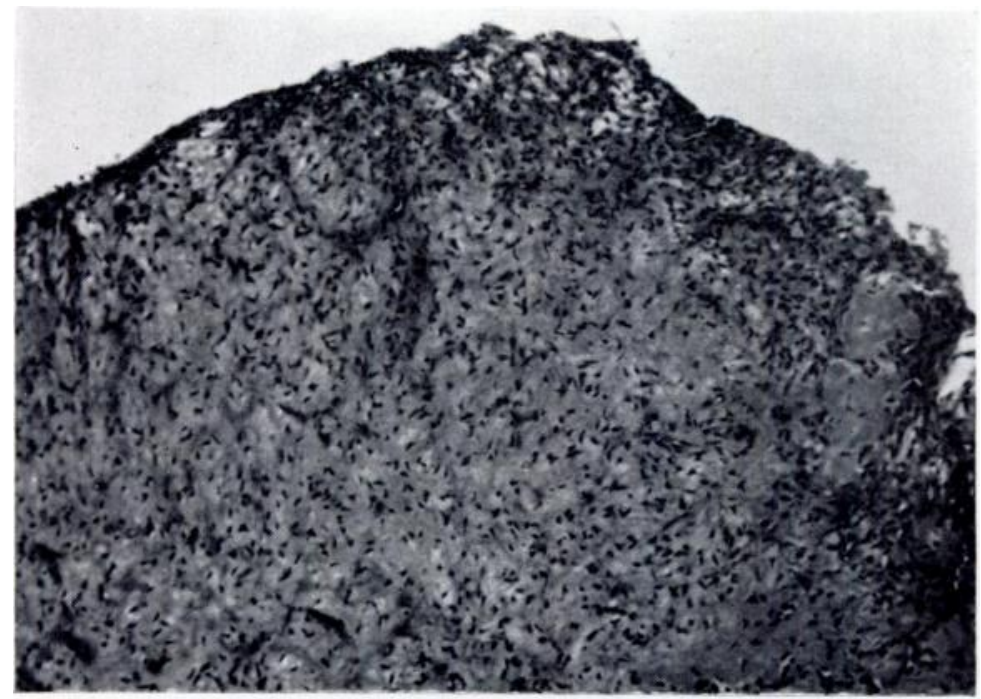

Fig. 2

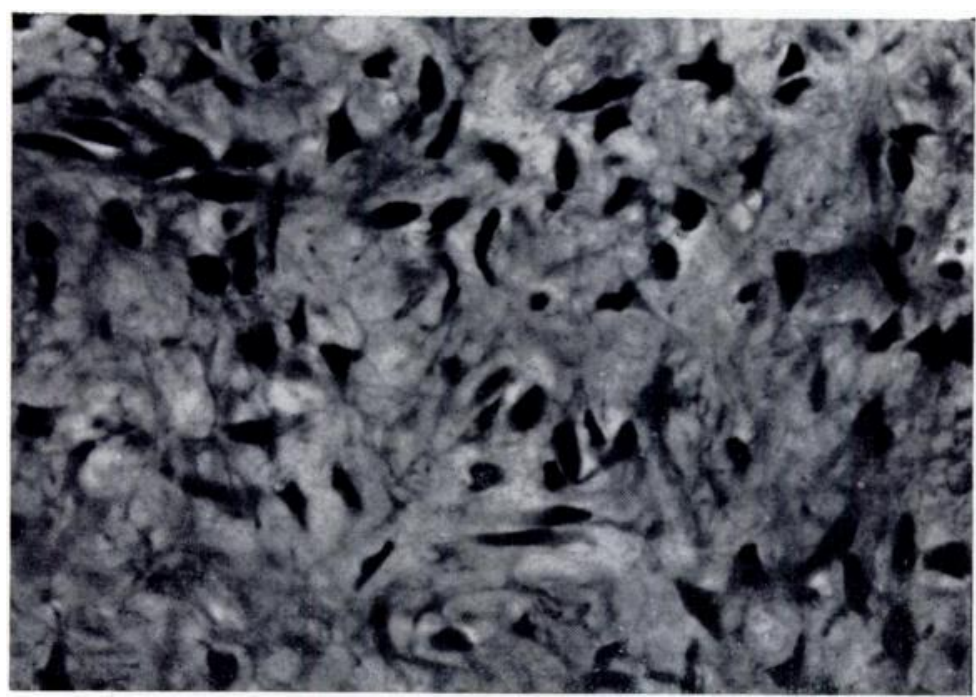

FIG. 3

Case 1-Histological appearances. Hyaline chondroid masses (Fig. 2) and fibroblastic cells in diffuse matrix containing delicate fibres and vacuoles(Fig. 3 ).

(Haematoxylin and eosin. Figure $2-\times 90$; Figure $3-\times 400$.)

Case 2 (Mr G. H. Pearce's case)-A girl aged fourteen was seen in September 1959 complaining of a painful swelling of the great toe of ten weeks' duration. The swelling was slightly tender and there was slight pain at the extremes of movement of the toe.

Radiographs showed a very well defined and rounded defect in the base of the proximal phalanx, extending to the overlying cortex (Fig. 4).

VOL. 44 B, NO. 1, FEBRUARY 1962 
At operation a month later a cavity containing "thin clear fluid" was found lined by membranous material. The surrounding bony wall was hard. The lining was curetted out but it was thought unwise to attempt obliteration of the cavity by filling it with bone chips.

Subsequent progress was promising, and by January 1960 there was only slight residual swelling and the girl had no symptoms. Radiographs showed that obliteration of the cavity was occurring. However, in October 1960 there was recurrence of aching pain with a little swelling and tenderness. Radiographs then showed a new area of destruction (Fig. 5). Treatment of this undoubted recurrence is now being considered.

Histological examination (Dr H. A. Sissons) showed abundant " chondroid " tissue with spindle-shaped and stellate cells and abundant myxoid intercellular material. Foci of large multinucleated giant cells were present in some areas, surrounded by small areas of more cellular tissue. Dr Sissons considered that the appearances were characteristic of chondromyxoid fibroma (Fig. 21).

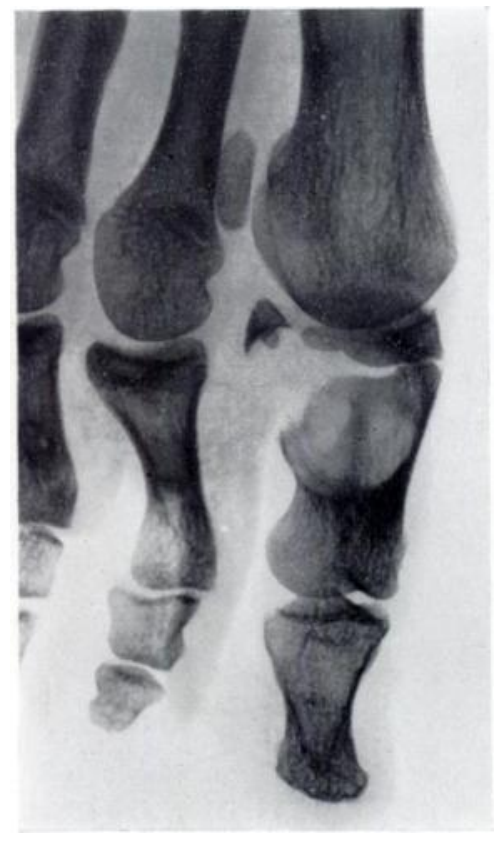

FIG. 4

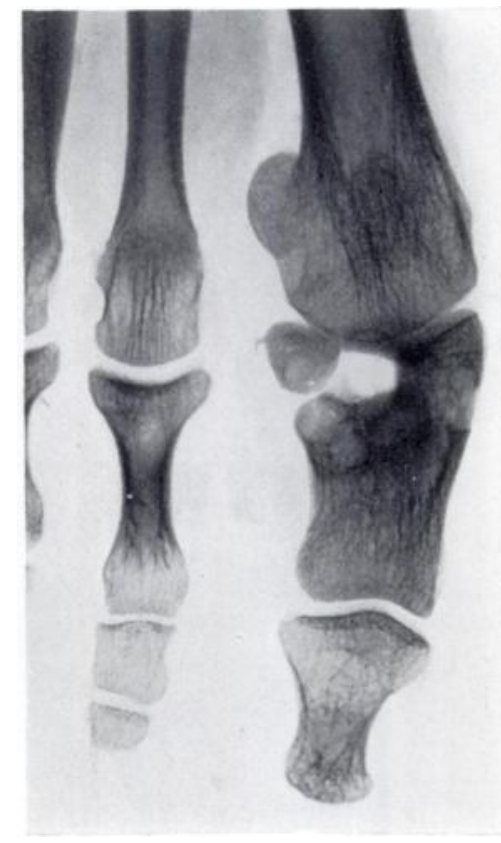

FIG. 5

Case 2. Figure 4-Radiograph showing tumour involving almost the whole width of proximal phalanx and extending into the epiphysis. Figure 5-Radiograph taken one year after treatment by curettage, showing recurrence of tumour at medial side of phalanx.

Case 3 (Mr J. S. Batchelor's case)-A boy of eight was admitted to hospital in October 1959 for investigation of a lump on the tibia. There was a history of a small swelling appearing shortly after the boy fell and grazed his knee five years previously. This persisted for nine months but then disappeared. The present swelling had reappeared during the previous three months and was not painful unless touched.

The hard, tender swelling was situated about two inches below the knee. It was about 6.5 centimetres in size, had a well defined edge and was not fixed to the overlying skin. Radiographs showed the appearances of a cyst in the bone (Fig. 6). At biopsy a cavity containing fat-like material was found. The first histological examination showed appearances of oedematous fibroblastic tissue.

Examining the tumour in November 1959, Dr H. A. Sissons reported that the lesion had the characteristic histological appearance of a chondromyxoid fibroma. It consisted of spindleshaped and stellate cells with abundant chondromyxoid intercellular material (Fig. 16). 
In December 1959 the cyst was opened again, its contents were evacuated and its walls curetted thoroughly. Bone from the edge of the opening was packed into the cavity.

Two months later the plaster was removed and the local condition appeared satisfactory. At the time of writing no further report of progress was available. Case 4 (Mr K. I. Nissen's case)-A housewife aged thirty-two was admitted to hospital in June 1953 with a swelling on the dorsum of the wrist. About one year before she had started to have pain, and swelling followed. Six weeks before admission she had fallen and hurt her wrist, but the pain since then was much as before the accident. There was no other history of injury. The swelling was tender, hard and fixed.

Radiographs showed an osteolytic lesion in the medial part of the lower end of the radius occupying about half the width of the bone and expanding it medially (Fig. 7). There was trabeculation in the more superficial but not in the deeper parts. The superolateral part of the area was bounded by a thin layer of dense bone.

At operation in June 1953 the cavity was opened, its gelatinous contents were curetted out, its hard floor was roughened and it was packed with cancellous bone chips.

By November 1953 the wrist was pain free and was recorded as "very satisfactory." The radiographs showed sound consolidation of the grafted bone, which obliterated the cavity.

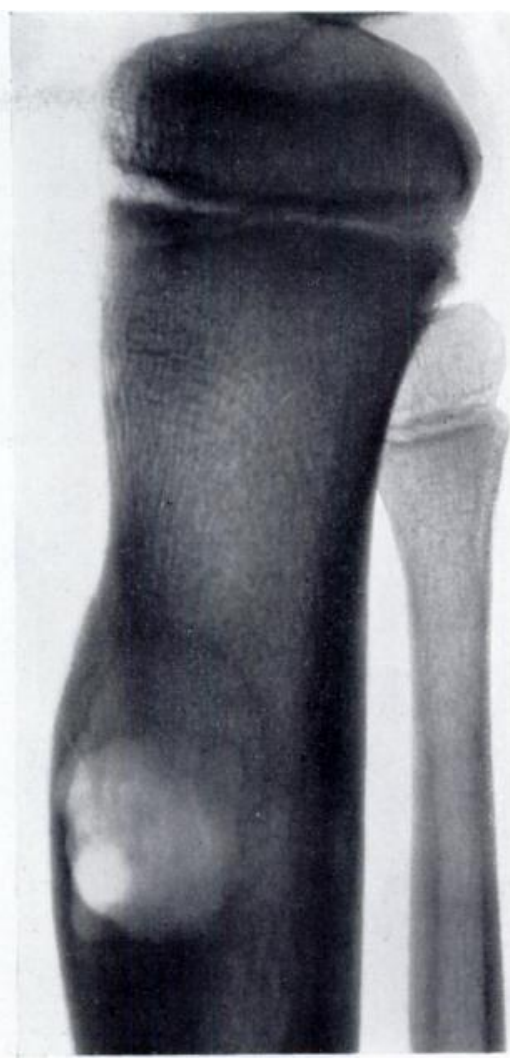

Fig. 6

Case 3-Radiograph showing lesion of tibia. It is situated farther from the metaphysis than usual and there is more than usual cortical thickening.

Histological examination (Dr P. C. Meyer) showed appearances characteristic of chondromyxoid fibroma. There was connective tissue composed of spindle cells separated by mucoid material. The cellularity was more marked in the region of blood vessels where groups of multinucleated giant cells were a prominent feature (Fig. 17).

Case 5 (Mr E. Mervyn Evans's case)-A boy of thirteen complained of a lump on the upper tibia which had been first noticed about one year before.

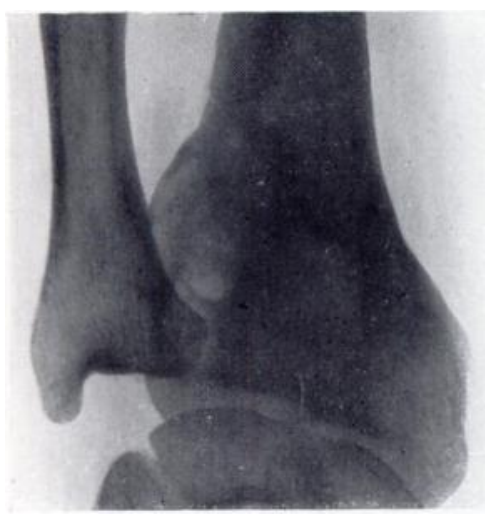

Fig. 7

Case 4-Radiograph showing lesion in the lower radius. It was tender and caused him to limp but was not very painful. The radiographs showed a clearly defined eccentric defect in the metaphysis without an overlying bony shell but with a thin layer of compact bone defining the deep margin (Fig. 8).

At operation in February 1957 the tumour tissue was found to be solid, greyish material invading periosteum and a small part of the epiphysial plate. The tumour was scooped out and the walls of the cavity were curetted, the defect being then closed with a sliding cortical graft and some cancellous chips.

The first impression was that this tumour might be a chondrosarcoma, but histological examination (Professor J. Gough and Professor S. L. Baker) showed it to be a chondromyxoid fibroma. Professor Gough

VOl. 44 B, NO. 1, FEBRUARY 1962 


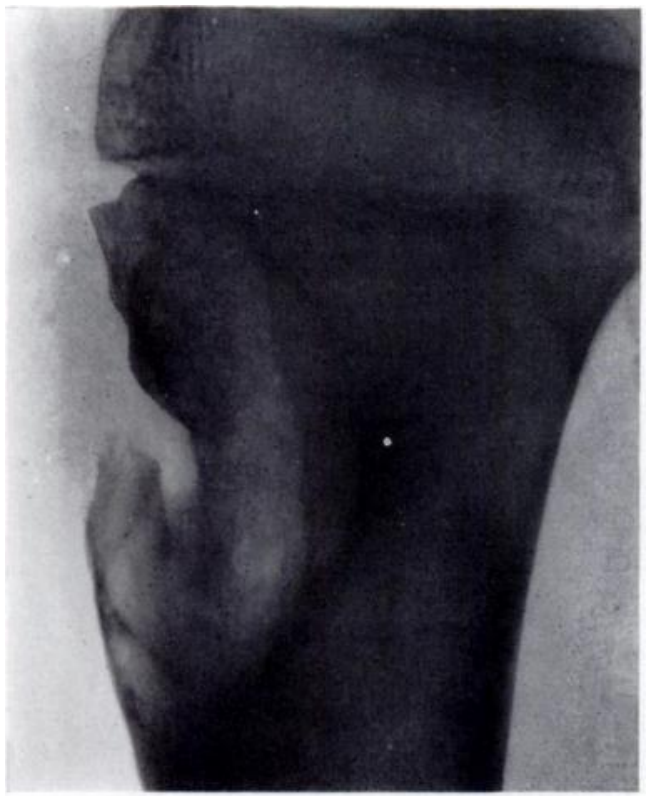

described it as a myxomatous tumour, eroding bone. There were areas containing blood pigment. Giant cells were plentiful in one region and were found occasionally scattered singly elsewhere. There was a fine collagenous matrix (Fig. 18).

Radiographs taken in March 1958 showed that the defect had completely filled in and the bone had remodelled so well that it was extremely difficult to detect any abnormality. When last seen in October 1959 the boy was symptom free and fully active, playing tennis and swimming.

Fig. 8

Case 5-Radiograph showing lesion in the upper tibia. Note the characteristic eccentric, metaphysial lesion limited by thin layer of compact bone.

Case 6 (Mr N. J. Blockey's case)-A boy of ten was admitted in September 1958 because of pain in and swelling of the right knee. Beginning as an ache in both lower limbs one year before, the pain had gradually become more severe and had localised in the right knee. The pain was worse at rest and in the morning but did not prevent normal activity. The father had noticed increasing fullness of the knee for several months. There was a swelling on the inner side of the thigh above the knee which was tender and rather warm. Movements of the knee were slightly limited by discomfort. There were no palpable glands.

Radiographs showed a large osteolytic lesion in the metaphysis of the femur involving almost half the width of the bone and showing deeper loculi reaching to the opposite cortex (Fig. 9). There were some trabeculae and there was a thin and incomplete shell of expanded bone over the superficial surface of the tumour.

At operation in September 1958 the cavity was opened and its contents were removed. They were described as being like redcurrant jelly. Later radiographs showed that removal had been incomplete, so a month later a second, radical clearance was done. The wall of the cavity was painted with phenol and the defect closed by packing with iliac bone chips and by inlaying a cortical graft from the tibia. The tissue removed weighed 77 grammes. The

Fici. 9

Case 6-Radiograph showing large loculated lesion of lower femoral metaphysis, retaining a thin shell of expanding cortex over its surface.

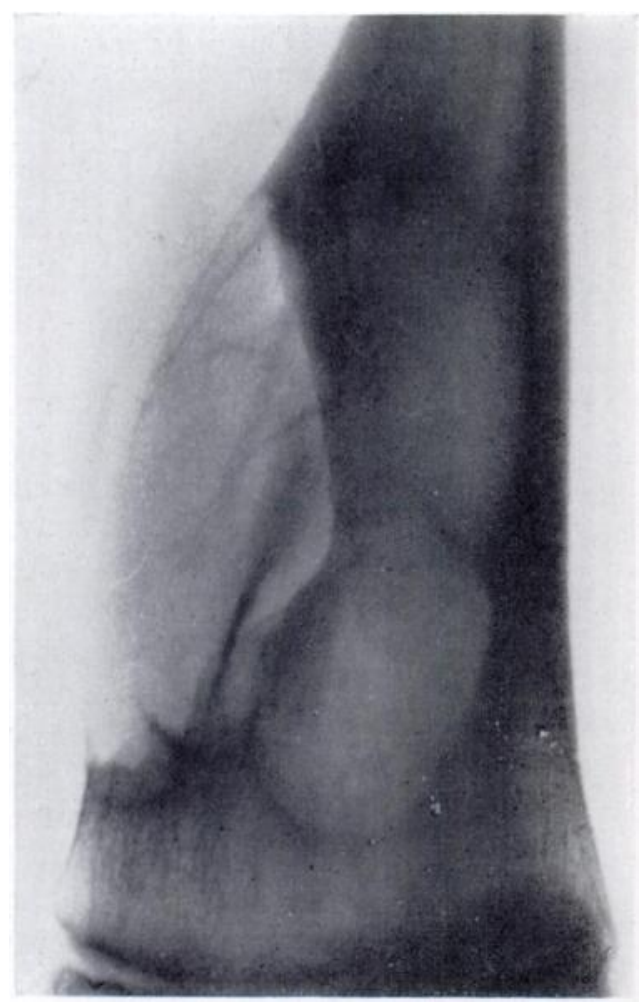

THE JOURNAL OF BONE AND JOINT SURGERY 
tumour was firm, pink and fleshy and had recognisable flecks of cartilage in it. The cortex of the femur was intact where it was recognisable. Histological examination (Dr A. M. McDonald) showed that it was a chondromyxoid fibroma. The histological pattern was remarkable for the large number of multinucleated giant cells present and the infrequency of the usual myxomatous degeneration typical of the neoplasm. Nodes of chondromatous tissue were evenly scattered through all the sections examined (Fig. 19).

When seen eight months after operation the patient had no complaints. There was slight overgrowth of the medial condyle causing knock-knee, but the result was very satisfactory. Radiographs showed good incorporation of the graft and no sign of recurrence.

Case 7 (Professor J. I. P. James's case)-A housewife aged twenty-two was referred from another hospital for follow-up of a supposed chondrosarcoma. The original lesion near the tibial tubercle (Fig. 10) had been operated on as a presumed cortical abscess in March 1950,

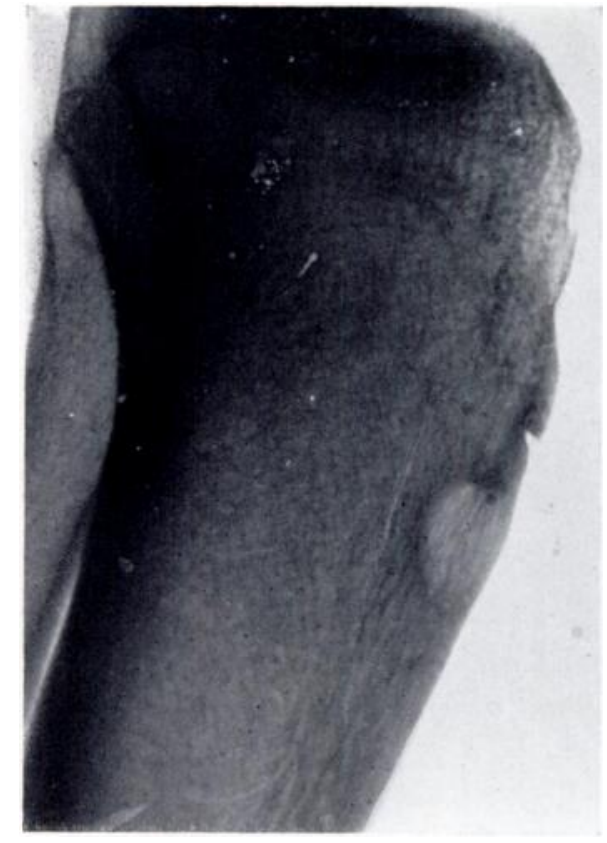

FIG. 10

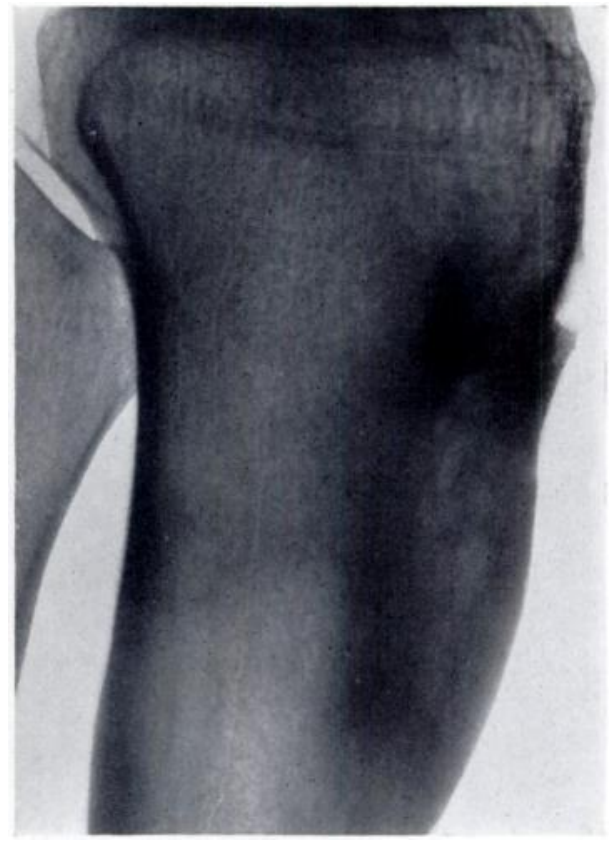

Fig. 11

Case 7. Figure 10-Radiograph showing small osteolytic lesion near tibial tubercle. Figure 11Radiograph taken thirty-three months later, after two operations for local excision. Note the increase in size of the lesion and the marked surrounding sclerosis.

and in September 1951 a large mass had appeared in the same region and had been excised. Histological examination of this had led to a diagnosis of chondrosarcoma.

On clinical examination there was only a little thickening medial to the operation scar, through which a little pus had recently discharged.

Radiographs showed a multilocular "cyst" rather larger than the original lesion and now surrounded by reactive sclerosis (Fig. 11). It lay just beneath the tibial tubercle and in one place seemed to reach the anterior surface through the cortex. There was no definite change during the next six months and although amputation was very seriously considered, it was finally decided to try a resection biopsy. Accordingly, in January 1953 a large block of bone containing the tumour was removed. There were several cartilaginous nodules on the anterior surface of the tibia involving the insertion of ligamentum patellae which had to be divided in order to remove the affected soft tissue. The bone defect was filled by a block of cadaveric bone and some cancellous chips.

VOL. 44 B, NO. 1, FEBRUARY 1962 
Examination of the specimen (Dr H. A. Sissons) confirmed that removal of the tumour had been complete. It was a nodulat and clearly demarcated mass surrounded by cancellous and cortical bone. It was made up of the spindle-selled tissue with abundant intercellular myxoid material that is characteristic of chondromyxoid fibroma. Examination of material from the previous operation specimen showed exactly the same histological structure (Fig. 22).

Subsequent progress was delayed by recurrent wound infection and several small Thiersch grafts and finally removal of some of the grafted bone were required. By the end of 1953 healing was complete. The patient was seen yearly until April 1958, and never had any complaints except occasional aching pain. There was full function of the knee and radiographs showed no sign of recurrence of the growth.

Case $8(\mathrm{Mr} \mathrm{W}$. D. Coltart's case)-A boy of fourteen came in August 1953 complaining of one month's pain in the left knee and of a swelling of the upper end of the tibia. A radiograph showed an eccentric lesion near the epiphysial line and covered posteriorly by a thin and

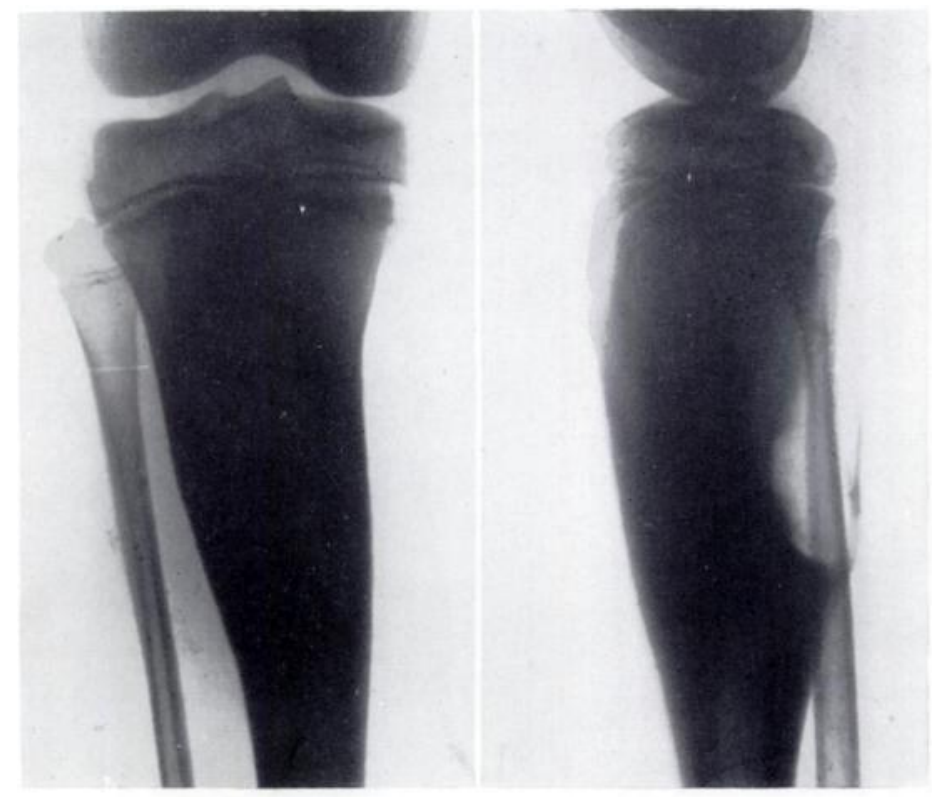

FIG. 12

Case 8-Antero-posterior (left) and lateral radiographs showing lesion of tibia. Note the extensive sclerosis.

incomplete shell of expanded bone (Fig. 12). Deep to the lower part of the well defined oval defect in the bone was marked sclerosis which extended across the full width of the tibia; new bone had also been laid down deep to the periosteum as it was pushed in front of the tumour and had formed a spur of bone at the inferior margin.

The tumour was scooped out and the space was filled with cancellous bone chips. Histological examination showed appearances which were thought to be those of fibroma or chondromyxoma.

Swelling and pain persisted. A further radiograph in April 1954 showed spreading sclerosis, thickening of the overlying shell of bone, and certainly no decrease in the size of the lesion. Eight months after the first operation the tumour was again scooped out but the amount of bone involved was so great that two months later a mid-thigh amputation had to be done.

The boy was alive and well five years later.

Examination of the amputated limb showed that the tumour was moderately soft and 


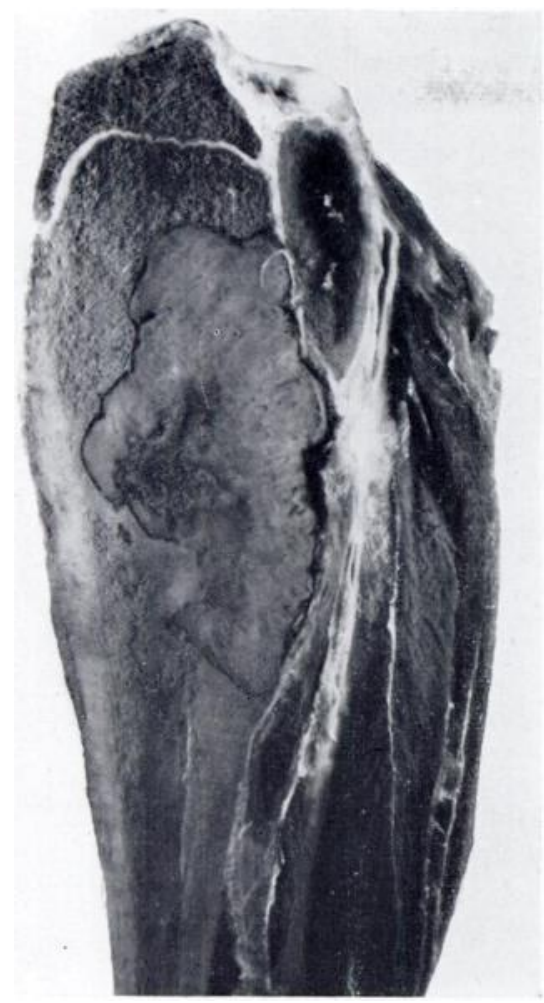

FIG. 13

Case 8-The amputated leg cut so as to show suggest that there has been invasion of muscle. the tumour. Macroscopic appearances do not

resilient with the translucent appearance of cartilage (Fig. 13). It was composed mainly of immature cartilage and myxomatous tissue. It did not seem to be involving the muscles.

Histological examination (Dr R. J. R. Cureton) showed that in the adjacent muscle there was much cellular collagen between atrophying muscle fibres. The atrophy and fibrosis of muscle was not of maximal intensity in the zone immediately adjacent to the tumour and resembled a fibrous neoplastic infiltration of the muscle rather than pressure atrophy and fibrosis. Areas were also noted in this fibrous tissue, where the matrix was distinctly blue with haematoxylin and eosin and resembled myxomatous tissue.

Professor Blacklock considered this to be a chondro-myxo-sarcoma. Dr Sissons, who also examined the material at this time, preferred to regard it as a chondromyxoid fibroma. He found that the tumour had the characteristic histological structure of chondromyxoid fibroma, consisting of spindle-celled tissue with abundant intercellular myxoid material. The same appearances were seen in the sections of material obtained at local excision and at amputation (Fig. 23).

Case 9 (Mr E. S. Evans's case)-A boy of nine came in November 1951 with a tender, ill defined, firm swelling about one inch in diameter near the tibial tubercle. This swelling had first been noticed two months previously.

The radiograph showed a very well defined defect in the lateral aspect of the upper tibia extending almost to the epiphysial line (Fig. 14). The deep surface was bounded by a thin complete layer of compact bone and in certain projections looked slightly lobulated. Superficially there was complete absence of bone over the tumour. There was no periosteal reaction but there was slight cortical thickening distal to the tumour where the contour suggested a localised failure of normal modelling of the growing bone.

The boy was examined at an orthopaedic conference, where it was recorded that the swelling was hot and that there was pulsation at its lower margin. The possibility that it might be a rapidly growing tumour led to exploration (December 1951) which revealed soft, pale gelatinous material filling a cavity whose smooth and sclerosed walls were lined by a thin membrane. Although the superficial cortex had been destroyed by the tumour there was no actual infiltration by the tumour tissue. The contents and lining membrane were removed but

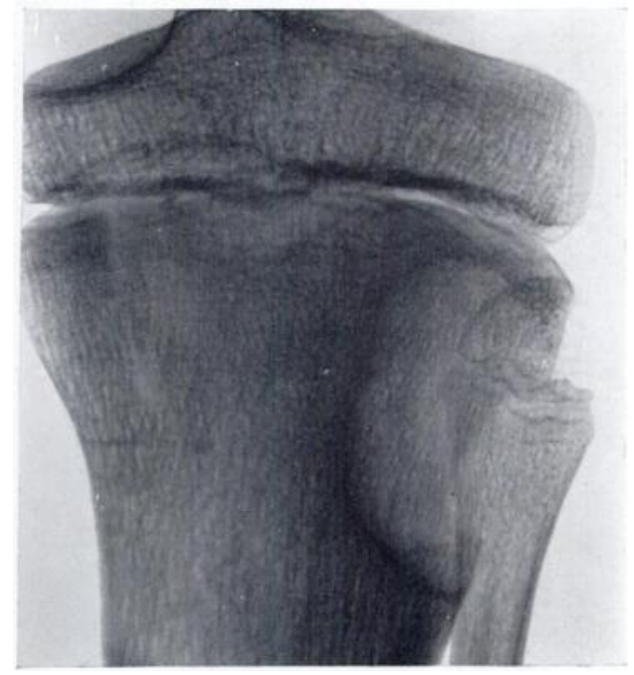

Fig. 14

Case 9-Radiograph showing well defined eccentric lesion of tibial metaphysis. 
the bony bed was not curetted. Histological examination showed appearances considered to be those of chondroma or osteoclastoma. The tumour was classed as benign.

The patient returned in January 1953 complaining that a soft tender swelling had returned after a blow on the leg. He was kept under observation and by February 1954 it was observed that this lump was slowly increasing in size. Radiographs taken shortly after operation showed periosteal reaction below the tumour site. This became progressively more distinct and in it there gradually appeared small translucencies and superficial irregularities. The original tumour site meanwhile gradually filled in although leaving the ghost outline of the original sclerotic margin.

A second operation in April 1954 revealed a myxomatous mass arising from the anterolateral surface of the tibia deep to the muscles. The same myxomatous material was found in the small "holes" in the bone corresponding to those seen on the radiographs and was similar to the tissue found at the first operation. Histological examination again showed appearances of a benign tumour.

Slight tenderness persisted for a while but when discharged in October 1957 the patient had had no symptoms or swelling for at least two years. Radiographs showed obliteration of the tumour to be complete apart from the presence of one or two small cystic areas in the superficial part of the thickened cortex.

Reappraisal of the histological appearances was undertaken by Dr H. A. Sissons. He reported that the lesion had the characteristic histological structure of benign chondromyxoid fibroma of bone. Nodular masses of tumour tissue were sometimes surrounded by cellular stroma containing reactive giant cells. In some areas the tumour tissue was adjacent to, but did not invade muscle (Fig. 20).

\section{REVIEW OF HISTOPATHOLOGY *}

The basic histological pattern of this tumour is of lobulated areas of myxomatous tissue, with a tendency to chondroid differentiation, separated by fibrocellular bands (Figs. 15 to 20).

The lobules are composed of irregularly disposed, elongated, branching cells, with stellate nuclei and an indistinct cytoplasm. The cells are separated by an amorphous substance, faintly eosinophilic in its staining reaction (Figs. 22 and 23). In the centre of a lobule the cells tend to be few in number, but they become more numerous at the periphery, where they are more regular in outline and resemble fibroblasts. These condensed peripheral zones, together with narrow intervening bands of fibroblasts in which blood vessels run, effect the separation of adjacent myxoid lobules. In the fibrous tissue blood vessels and multinucleated giant cells of the osteoclast variety may be observed (Figs. 17, 19 and 21).

The interstitial matrix of the myxoid tissue may become denser and more hyaline in appearance, resembling thereby the matrix of cartilage (Fig. 16). The cells in these areas may or may not adopt a rounder shape, more in keeping with that of chondrocytes, and they may even lie in lacunae. In those areas where chondroid differentiation is present the lobulation of the tissue may be due to differences in the staining propelties of the matrices: myxoid areas appearing as pale zones and the chondroid as darker zones, with no intervening fibrous band.

Upon this basic pattern quite wide variations can occur even within the same tumour, and a final diagnosis may depend upon examination of several sections. Large areas may be seen where distinctive lobulation is not apparent, and here the tissue may be myxoid or cartilaginous in appearance; or there may be large regions of fibrous tissue, associated with a few or moderate numbers of multinucleated giant cells, in which isolated lobules of more typically myxoid tissue may be found (Fig. 19). In some tumours the presence of tissue resembling benign chondroblastoma will be seen (Figs. 17 and 21). Here, or in other

\footnotetext{
* This review was prepared by Dr P. D. Byers, Institute of Orthopaedics, London.
} 
cartilaginous areas, flecks of calcification of the matrix have been reported (Dahlin 1957) although this is distinctly unusual.

In the myxoid areas reticulin is delicate and scanty at the centre, but becomes denser at the periphery of the lobules. The fibrocellular tissue shows the most abundant reticulin

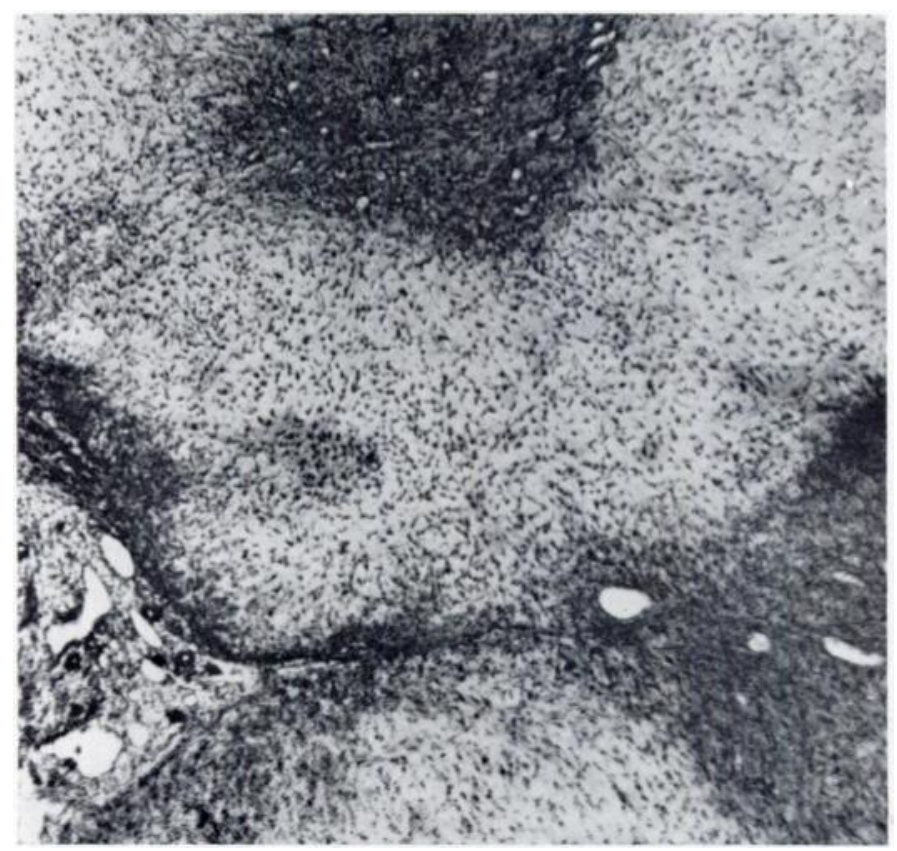

Fig. 15

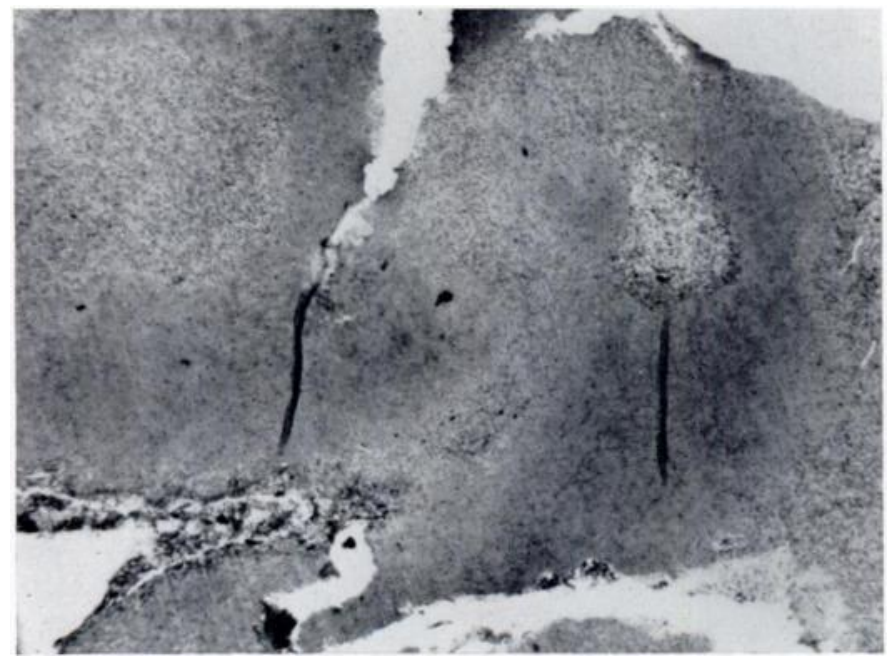

FIG. 16

Case 3-Histological appearances. Figure 15-Lobules of myxoid tissue with peripheral condensation of cells, separated by vascular fibrous tissues. (Masson trichrome, $\times 45$.) Figure 16 - Some lobules show chondroid differentiation at their peripheries. (Haematoxylin and eosin, $\times 22$.)

fibrils; while the chondroid areas have a moderate number. Special stains do not show the presence of fat, or of material showing a positive periodic acid Schiff (P.A.S.) reaction. The chondroid areas may be metachromatic, and stain with Alcian blue.

VOL. 44 B, NO. 1, FEBRUARY 1962 


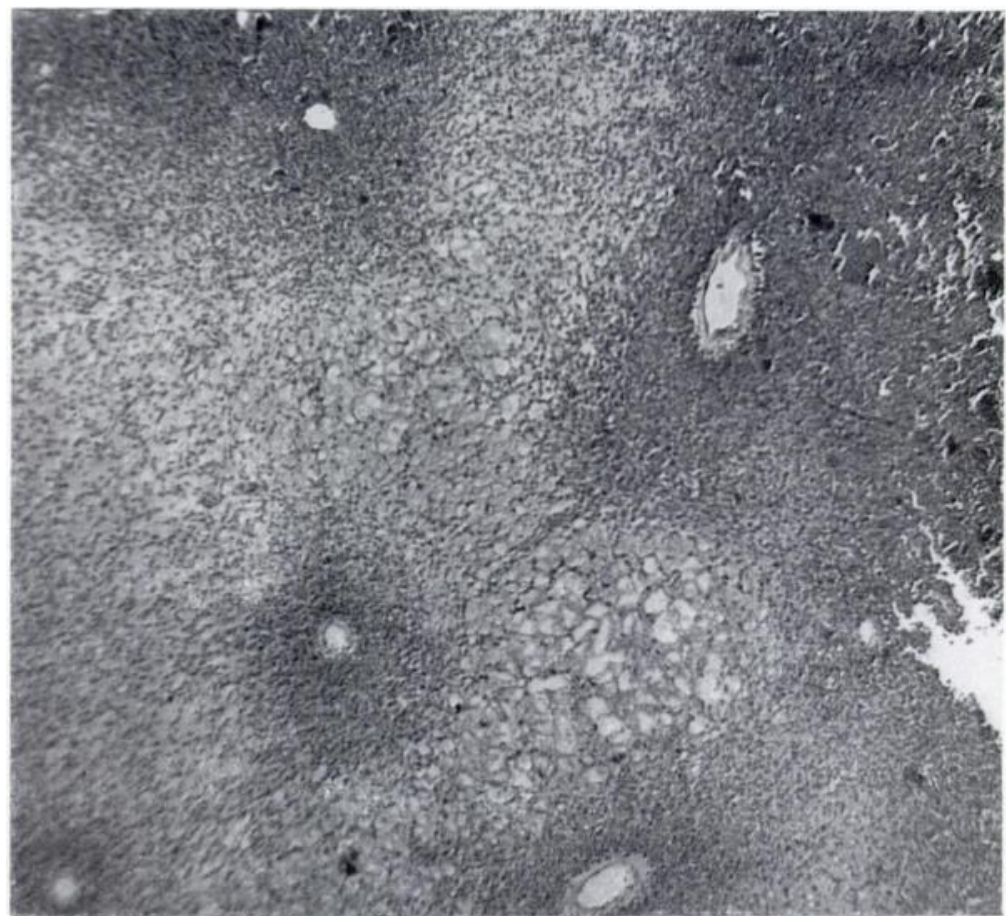

FIG. 17

Case 4-Histological appearances. Irregularly lobulated area of loose myxoid tissue with peripheral bands of tissue resembling chondroblastoma: multinucleated giant cells present. (Haematoxylin and eosin, 50.)

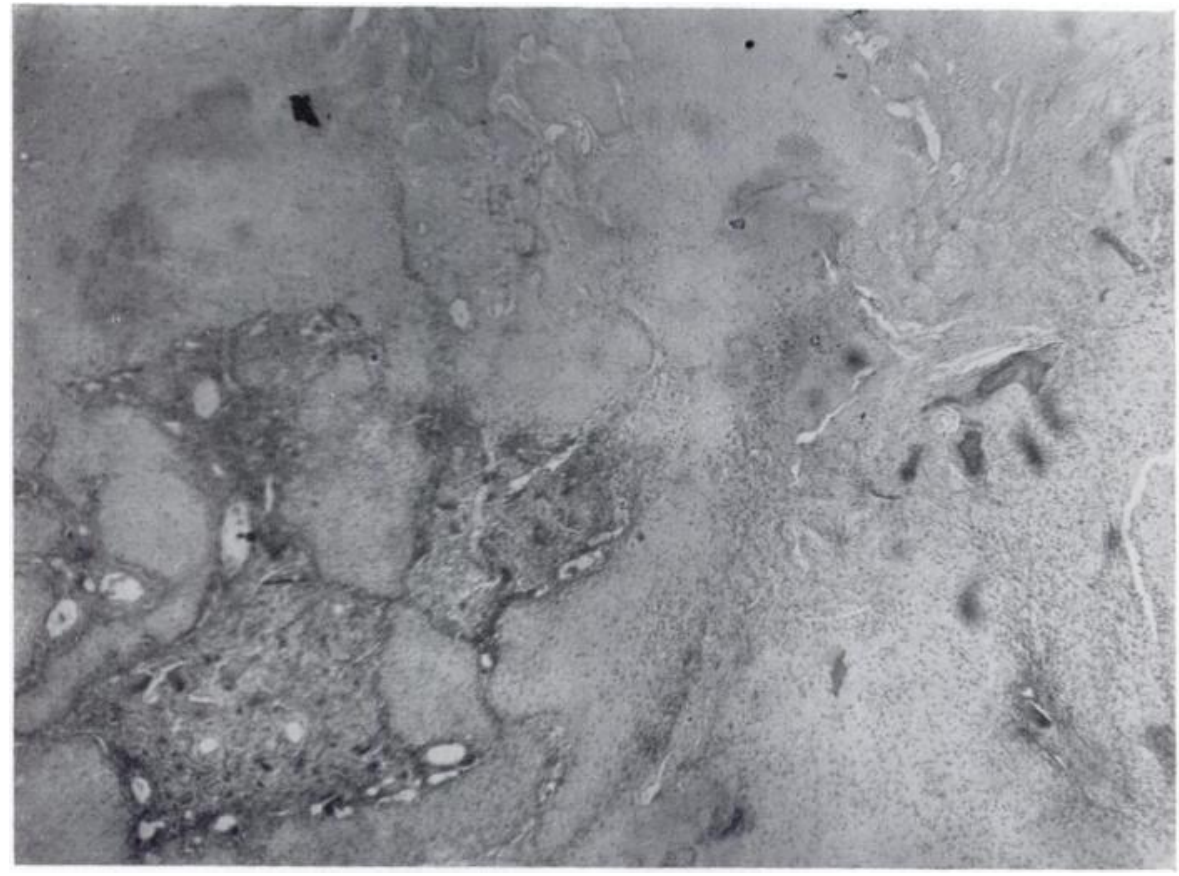

Fig. 18

Case 5-Histological appearances. Lobulated chondromyxoid tissue with a small area of bony differentiation. (Haematoxylin and eosin, 60.) 


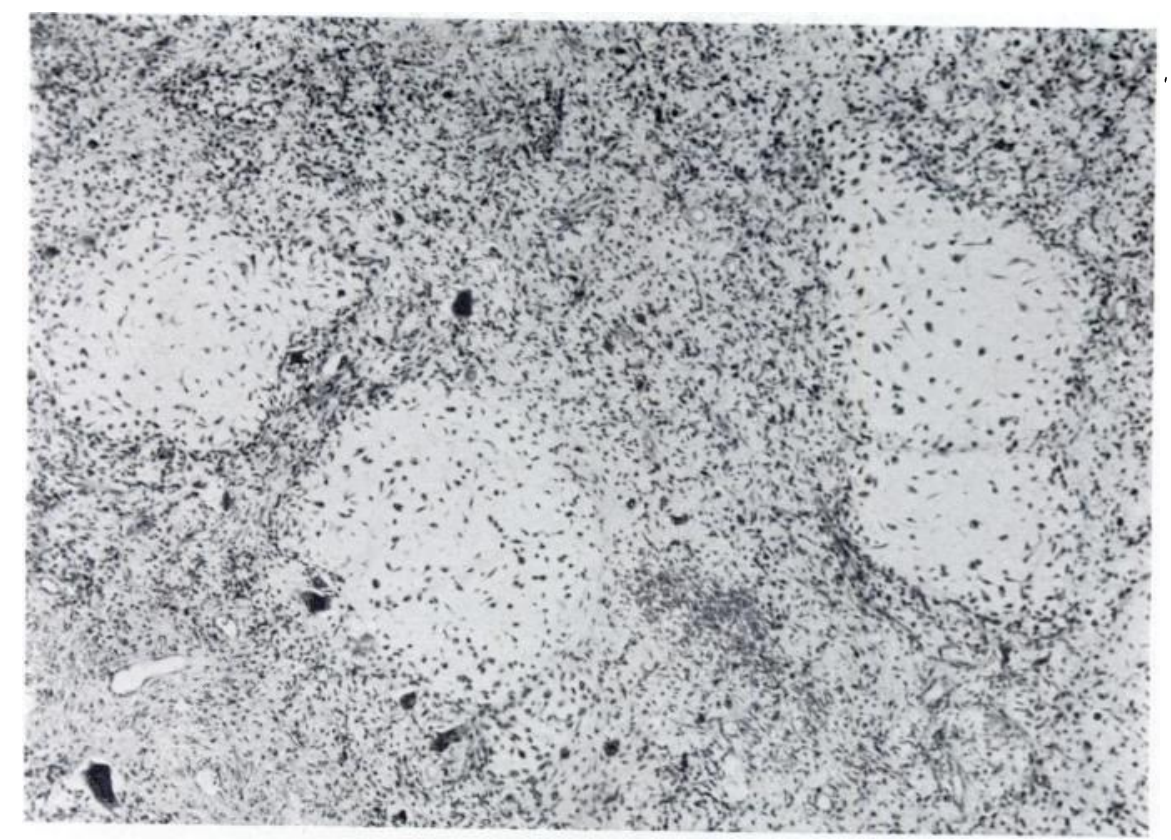

Fig. 19

Case 6. Histological appearances. Small lobules of myxoid tissue showing somecartilaginous features separated by large amounts of fibrous tissue containing multinucleated giant cells. (Haematoxylin and eosin, $\times 90$.)

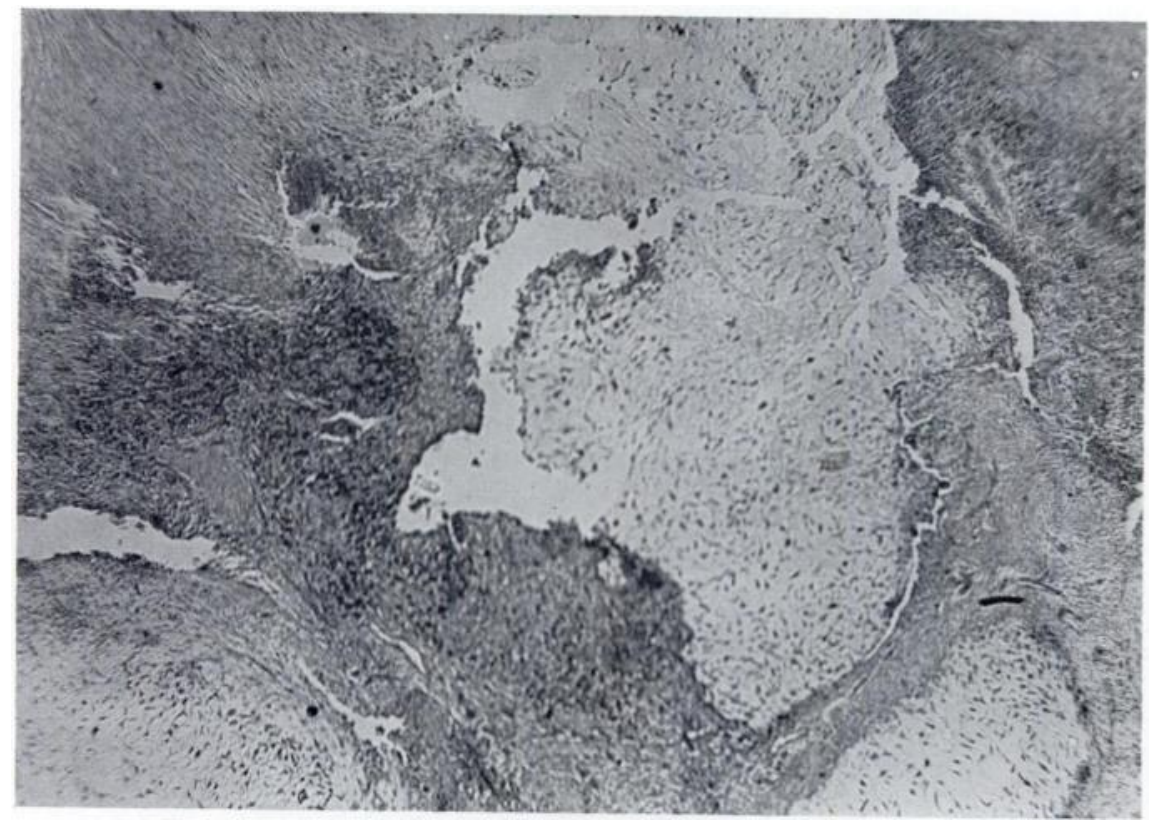

Fig. 20

Case 9-Histological appearances. Islands of myxoid tissue with little peripheral condensation of cells, separated by bands of fibrous tissue containing haemosiderin. (Haematoxylin and eosin, $\times 63$.) 


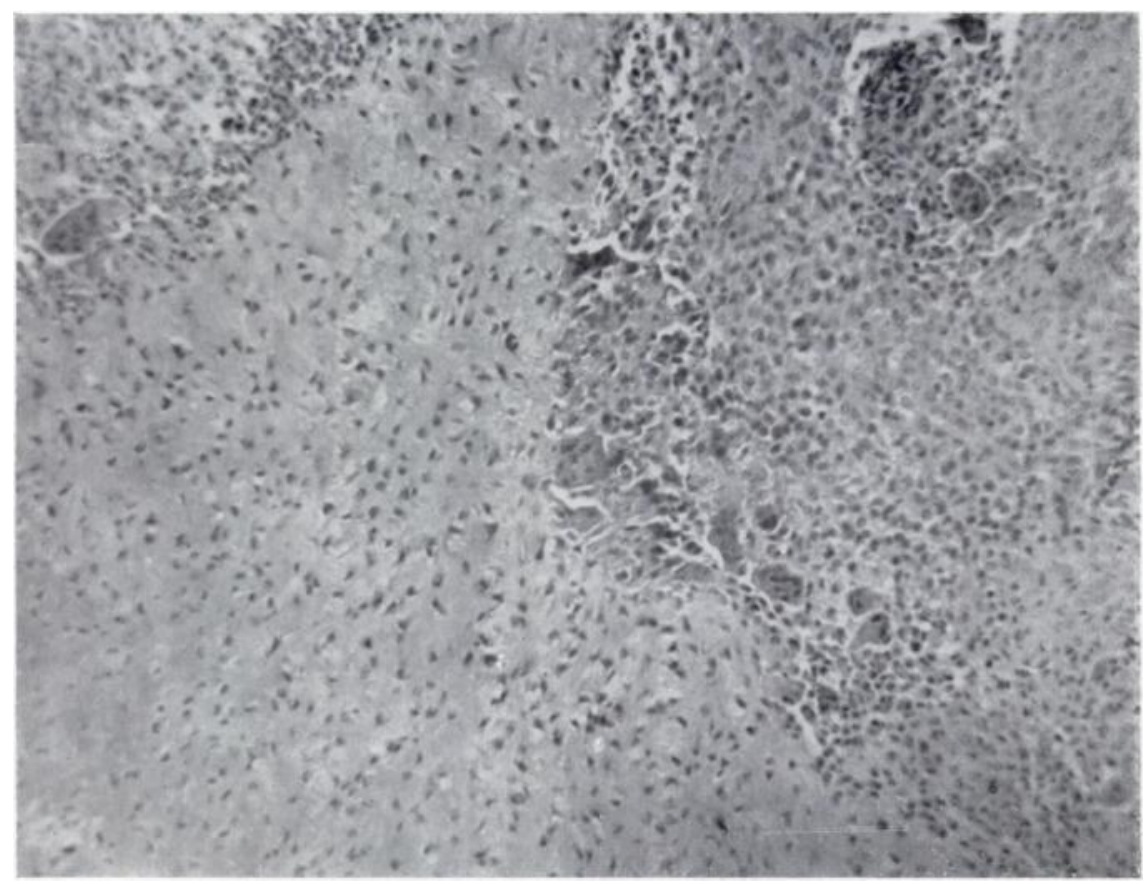

Fic. 21

Case 2-Histological appearances. Myxoid tissue with some cartilaginous features surrounded by tissue resembling benign chondroblastoma containing multinucleated giant cells. (Haematoxylin and eosin, $\therefore 120$.)

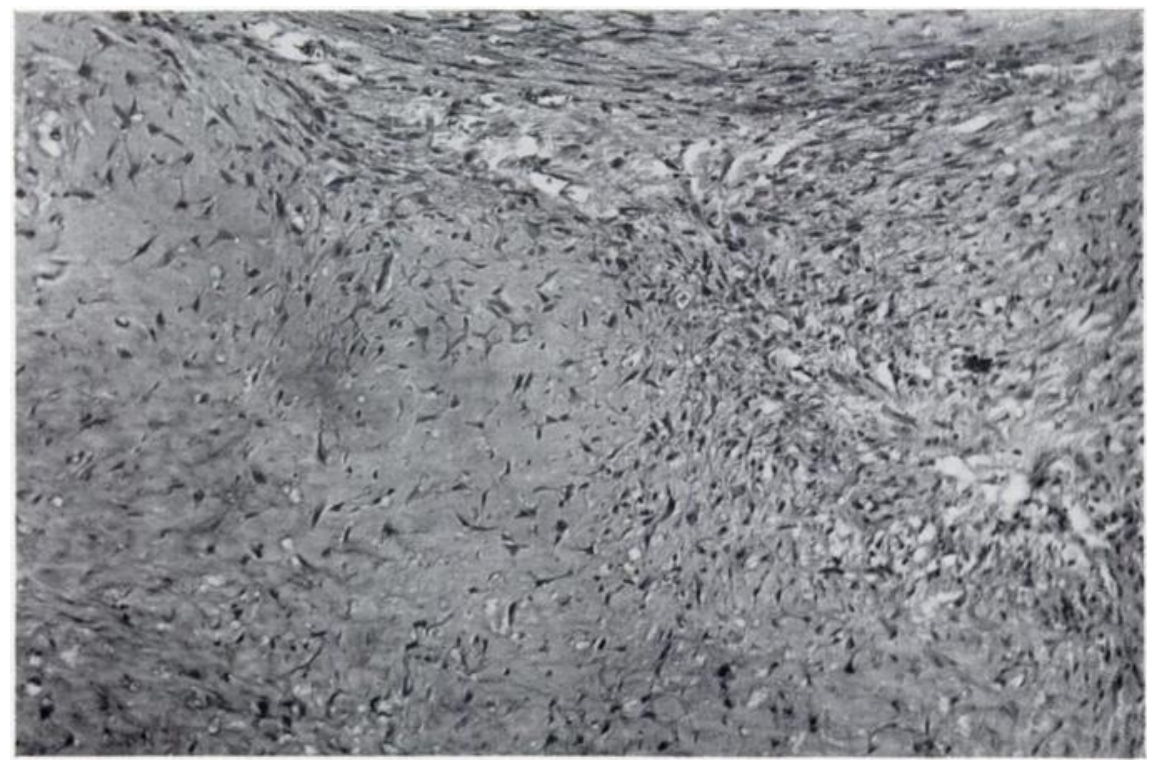

Fig. 22

Case 7-Histological appearances. The margin of two lobules of myxoid tissue separated by a band of fibrous tissue. (Haematoxylin and eosin, $\times 120$.) 
In the present series several of these variations were demonstrated. In Case 1 the differences of opinion appear in part to be due to inadequate material. In two cases a few peripheral areas resembling benign chondroblastoma are present (Figs. 17 and 21). In Case 5 (Fig. 18) there is an irregular island of bony differentiation where trabeculae of osteoid have been laid down by osteoblasts; in the intervening spaces is a loose connective tissue containing giant cells. This appears to be part of the tumour rather than reactive bone formation. Isolated trabeculae of woven bone are also present. In Case 6 much of the material is of a rather fibrous character with fairly numerous giant cells scattered through it and a few islands of typical myxoid tissue lying in it (Fig. 19). This latter tissue contains no giant cells. In Cases 3 and 8 there is very irregular lobulation and extensive areas of the tumour show chondroid differentiation of the matrix, which stains more deeply, thereby differentiating the tissue from the paler staining matrix of adjacent myxoid areas (Figs. 16 and 23). In Cases 3 and 9 quite prominent collections of haemosiderin pigment were seen. These were mainly in peripheral parts of the tumour, lying in the fibrous tissue bands (Fig. 20).

\section{DISCUSSION}

The cases in the present series resembled in most respects those previously

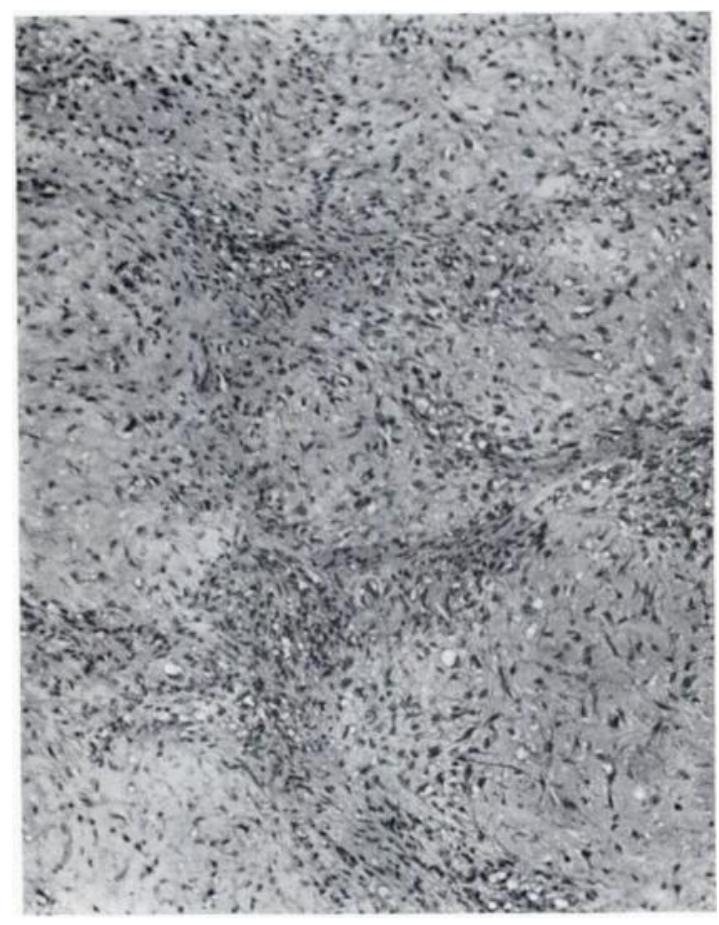

Fig. 23

Case 8-Histological appearances. Lobules of tissue with some chondroid differentiation of matrix separated by fibrocellular bands. (Haematoxylin and eosin, $\therefore 95$.) described. The patients were, however, rather younger than earlier reports have shown. The average age was seventeen and a half but two were in the first decade and six were under fifteen. In the thirty-seven previously reported cases (thirty-six of which were reviewed by Iwata and Coley (1958)) the highest incidence was in the third decade and was slightly less in the second decade. Only one patient was in the first decade of life.

Eight of the nine tumours were in the lower limb. Five were in the common site in the proximal end of tibia, two were respectively in the femur and in the fibula, both near the knee, and one was in a toe. The only one in the upper limb was in the radius, a site not reported before.

Radiographic appearances-When the radiographic appearances of previously recorded cases are compared with those of the present series it is found that many conform to a fairly characteristic pattern. Case 6 showed a particularly large trabeculated tumour causing much expansion of bone. In Cases 5 and 9 the lesions were smaller with less expansion, had no shell over them, and appeared as a "bite" out of the bone. The lesions in Cases 1, 3, 4 and 8 were basically similar but each showed variations. In Case 1 there was punctate calcification in the tumour, which has occurred in only one previous case (Dahlin 1957) and is not typical. In Case 3 the tumour was well away from the metaphysis and had more cortical thickening and a thicker bony shell than all the others. In Case 4 there was a suggestion of spicular bone reaction at the edge of the tumour, and in Case 8 there was very much more sclerosis 
around the tumour than in any other. This may possibly be related to its more malignant behaviour.

In Case 2 there was involvement of almost the whole width of the proximal phalanx of the great toe. The lesion differed from the others in not having any distinct marginal sclerosis although it had produced a very clear-cut defect. It is particularly interesting that it had crossed the epiphysial line. This has been observed in other cases, and Dr Byers notes that there were parts of this tumour resembling benign chondroblastoma, a tumour which commonly appears in an epiphysis. Lichtenstein (1959) states that the fifteen examples of this mixed tumour that he has seen mostly came from bones of the foot.

In Case 5 the tumour was found at operation to be invading the epiphysial plate, but this is not apparent from the radiograph since it had not yet entered the epiphysis. The tumour in Case 7 was very small when first discovered, and although the radiographic changes are essentially the same as with some of the larger tumours, it is obviously much more difficult to diagnose correctly at this stage.

Radiological diagnosis-The radiologist usually makes the diagnosis of bone cyst or chondroma. Both tend to occur more centrally in the long bones but the "acute" bone cyst is more often subcortical (Geschickter and Copeland 1949) and chondromata may also be subcortical. Chondromata may also show some calcification and are uncommon in long bones of young people.

A well defined area of fibrous dysplasia might give a similar appearance unless it had the characteristic " ground-glass" translucency. Non-osteogenic fibroma (metaphysial fibrous defect) most nearly mimics the chondromyxoid fibroma. One has the personal impression that the trabeculation which often occurs in non-osteogenic fibroma is thicker and coarser than in chondromyxoid fibroma. Aneurysmal bone cyst might also on some occasions be indistinguishable on a radiograph.

As with other bone tumours, the radiograph alone is not diagnostic. The difficulty lies not so much in variations from a recognisable pattern as in the fact that other and commoner lesions may look the same. Were chondromyxoid fibroma not a rarity it would probably be considered no more difficult to diagnose radiologically than other bone tumours.

Results of treatment-Treatment by curettage (twenty-six cases) has been successful in the cases previously reported, but since five recurred it is probably better to resect completely. The follow-up period ranges from a few months to eighteen years. There has been no death. On this evidence the tumour is considered benign, in spite of the deceptively malignant histology, and amputation is to be avoided. No chondromyxoid fibroma was known to have become malignant until the report of Iwata and Coley (1958), who included one such case in their series of six. This lesion recurred twice after local resection, and on the last occasion was diagnosed histologically as having altered in character and become a low-grade chondrosarcoma. Thirteen months after amputation there had been no recurrence. Since this is the only known occasion on which amputation has been done (except for Case 8 of the present series) the possibility of unnecessary amputation has so far been avoided, or it has passed unrecognised.

In four of the nine cases now described the tumour recurred after operation. (In Case 6 curettage was carried out twice because it was immediately realised that the first attempt had been inadequate.) This relatively high rate of recurrence does not greatly affect a statistical analysis of all reported cases, but in this small series it is quite striking and requires further consideration. The lesion in Case 7 was at first thought to be a small bone abscess and may not have been curetted very thoroughly. In Case 9 the tumour was removed with the membranous covering surrounding it, but the bony bed was not curetted. In each case the recurrent tumour tissue was found in soft tissue near the original lesion, and after a second operation the patients have remained well for five and three and a half years respectively. In Case 2 recurrence was recent and no second operation has yet been attempted. The tumour 
involved almost the whole width of a small bone. Such a situation makes total removal by curettage very difficult if a functional bone is to remain. The tumour of Case 8 is the most sinister of the series. Two attempts at curettage failed to halt its progress. Interpretation of the histology was uncertain, but amputation was finally done because there was too much destruction of the tibia to allow any alternative. The patient has now been under observation for five years and has shown no evidence of recurrence or metastasis.

The histology of these four tumours was not remarkable except in Case 2 which presented areas resembling benign chondroblastoma, but this is not likely to be significant.

The result in Cases 7 and 9 suggests that a second limited operation, either resection or even another curettage, can be successful, whereas the result in Case 8 (like that in Case 5 of Iwata and Coley) shows that occasionally a growth is sufficiently aggressive to require amputation.

The present series, therefore, shows two points of difference from the accepted patternyounger patients and a high rate of recurrence-which may be associated. In this connection Scagliettiand Stringa (1961) described five cases which they regarded as chondromyxoid fibromata but which they considered to "constitute a separate group distinguishable from typical chondromyxoid fibromata because of certain clinical and morphological characteristics." These characteristics are marked symptoms and rapid progress in children up to ten years of age, considerable bone reaction to the tumour and a strong tendency to rapid recurrence after curettage. Because there was much more myxoid than chondroid tissue they preferred to call these tumours " myxoma of bone in childhood."

They also pointed out that " the (previously) reported cases that did not follow a benign course occurred in younger patients, whose ages were nearer to those of our patients. Because the tumour is more aggressive in the younger patient it would appear that the younger the patient the more readily and, perhaps, more consistently will there be recurrence." Our experience does not confirm their separation of a clearly defined sub-group of " myxomata" but does tend to justify their general statement relating youth and aggressiveness in chondromyxoid fibromata.

The nature of the tumour-Two major related questions arise-can we justify separate classification of these tumours, and are they in fact benign? The answer to the first question depends largely on histological interpretation. The American authorities appear to have no doubt, but in this country there has been only one case previously reported, and there is only one other published reference to the tumour in the British literature (Sissons 1956). This probably reflects the opinion of many pathologists who do not yet feel that these tumours can be so distinctly separated as a homogeneous group. Willis (1953) lists them with certain other rare conditions under the heading "Other rare lesions of uncertain status," observing about them all that "It is too soon yet to come to firm conclusions about the histogenetic relationships of these to one another, to other well known bone tumours, and also to the several variants of fibrous dysplasia." Nevertheless, the diagnosis of chondromyxoid fibroma is, as the present reports show, being made increasingly often in this country.

The tumour has hitherto been considered an easily treated benign growth with little tendency to recurrence. It may, however, prove as these cases suggest, that recurrence after curettage is not so rare, particularly in those under the age of fifteen. Nevertheless, they should still be considered as benign tumours. Most of the tumours in the recorded cases have responded well to simple operative measures, and the more malignant behaviour of a few (so far restricted to local recurrence of aggressiveness) may be compared with many other kinds of tumour which we are prepared to call benign in the full knowledge that there is no absolute division between " benign " and " malignant."

Only prolonged observation will reveal the ultimate result. The most important question facing the surgeon is whether the tumour will metastasise unless he does an immediate amputation. On present evidence the answer seems to be that it will not metastasise. It can 
be treated by local resection or curettage and if this fails a second attempt may succeed. A very few will continue to grow until amputation is the only practical solution, but there is no evidence yet that anything is lost by delay.

Whatever the histogenetic relationships of the tumours may prove to be, experience so far shows that they comprise a group which in the past have frequently misled pathologists into a confident diagnosis of malignancy, and yet which usually behave in a benign fashion.

If one believes with Lichtenstein (1959) that " more mischief is done currently through over diagnosis than through failure to recognise malignant neoplasms promptly" this alone will justify attempts to separate them. The author has accepted chondromyxoid fibroma as a suitable designation for these lesions, the exact name under which they are classified appearing to be of secondary importance.

\section{SUMMARY}

In 1948 Jaffe and Lichtenstein published a series of bone tumours as chondromyxoid fibromata, stressing that this newly recognised entity was likely to be mistaken for chondrosarcoma but was a benign growth. The accumulated experience of thirty-seven cases, which are all that have been recorded in detail, is briefly reviewed. A further series of nine similar cases is reported here and comparisons are made which show general agreement with the experiences and conclusions of earlier authors. It is however suggested that the tendency to recur may have been underestimated, particularly in younger patients.

These nine cases have been collected from as many hospitals in Britain and I am greatly indebted to the surgeons, pathologists and radiologists concerned for permission to use their records.

I have also had a great deal of assistance from Dr H. A. Sissons of the Department of Morbid Anatomy at the Institute of Orthopaedics in tracing and reviewing these cases, and from Dr P. D. Byers of the same department who kindly wrote the section on histopathology which is included in this review.

\section{REFERENCES}

Dahlin, D. C. (1956): Chondromyxoid Fibroma of Bone, with Emphasis on its Morphological Relationship to Benign Chondroblastoma. Cancer, 9, 195.

Dahlin, D. C. (1957): Bone Tumors. Oxford: Blackwell Scientific Publications Ltd.

Dahlin, D. C., Wells, A. H., and Henderson, E. D. (1953): Chondromyxoid Fibroma of Bone: Report of Two Cases. Journal of Bone and Joint Surgery, 35-A, 831.

Geschickter, C. F., and Copeland, M. M. (1949): Tumors of Bone. Third edition. Philadelphia, London, Montreal: J. B. Lippincott Company.

Hutchison, J., and PARK, W. W. (1960): Chondromyxoid Fibroma of Bone. Report of a Case. Journal of Bone and Joint Surgery, 42-B, 542.

Iwata, S., and Coley, B. L. (1958): Report of Six Cases of Chondromyxoid Fibroma of Bone. Surgery, G.'necology and Obstetrics, 107, 571.

JAFFe, H. L. (1958): Tumors and Tumorous Conditions of the Bones and Joints. London: Henry Kimpton.

Jaffe, H. L., and Lichtenstein, L. (1948): Chondromyxoid Fibroma of Bone. A Distinctive Benign Tumor Likely to be Mistaken Especially for Chondrosarcoma. Archives of Pathology, 45, 541.

Lichtenstein, L. (1959): Bone Tumors. Second edition. London: Henry Kimpton.

Scaglietti, O., and Stringa, G. (1961): Myxoma of Bone in Childhood. Journal of Bone and Joint Surgery, 43-A, 67.

Sissons, H. A. (1956): Giant Cell Tumour Variants. Proceedings of the Royal Society of Medicine (Section of Pathology with Section of Orthopaedics), 49, 416.

Willis, R. A. (1953): Pathology of Tumours. Second edition, p. 686. London: Butterworth and Co. (Publishers) Ltd.

Wrenn, R. N., and Sмith, A. G. (1954): Chondromyxoid Fibroma. Southern Medical Journal, 47, 848. 